\title{
Student Interaction with a Computer Tablet Exam Application Replicating the Traditional Paper Exam
}

\author{
Matthew J. Cheesman ${ }^{* 1}$, Prasad Chunduri ${ }^{1}$, Mary-Louise Manchadi ${ }^{1}$, Kay Colthorpe ${ }^{1}$, Ben Matthews ${ }^{2}$ \\ ${ }^{1}$ School of Biomedical Sciences, University of Queensland, Australia \\ ${ }^{2}$ School of Information Technology and Electrical Engineering, University of Queensland, Australia \\ "1m.cheesman@uq.edu.au; 1 p.chunduri@uq.edu.au; ${ }^{1}$ m.roymanchadi@uq.edu.au; ${ }^{1 k}$.colthorpe@uq.edu.au; ${ }^{2}$ matthews@uq.edu.au
}

\begin{abstract}
The purpose of this study was to develop a computer tablet-based examination application (TabExam) and to explore its potential to replace the traditional paper-based exams. It was completed in digital handwriting with a stylus pen and submitted online for marking and feedback. Comparisons of student exam scores on both the TabExam and a parallel traditional paperbased exam indicated no difference, suggesting that the change in exam mode did not affect academic performance. While students reported that the TabExam had some advantages over paper exams, they had a neutral view on using it as a complete replacement for paper-based exams. More than half of the students accessed the online feedback provided after the TabExam while none of the students requested feedback on their paper exams. In addition to the quantitative data, this paper also provides a students' perspective into aspects that they perceive as positive or negative, or need improvement, with regards to the use of tablets for examinations.
\end{abstract}

Keywords

Tablet Computers; Touch Screens; Written Tests; Digital Technology; Online Assessment; Feedback

\section{Introduction}

Many students enrolled in higher education today have been exposed to computers throughout their lives. Most are familiar with an array of computer softwares and are skilled at using computers for their learning needs (Kennedy et al., 2008). Indeed, students indicate that computer technologies are integral to learning, being central to how their learning is oriented and organised (Conole et al., 2008; Efferth, 2013).

Online assessment has also become increasingly popular, due to its effectiveness in promoting student engagement while providing a facile means by which to deliver meaningful student feedback (Gikandi et al., 2011). Online assessment tasks vary from assignments and reports, to self-assessment and peer-assisted projects (Gaytan \& McEwen, 2007; Mogey et al., 2010). However, online tests and examinations are predominantly formative, due to concerns over potential cheating (Wilkinson \& Rai, 2009). Furthermore, the question types utilised are typically multiple-choice or simplistic questions (Amelung et al., 2011) rather than essay-type questions, which can assess a greater complexity of student understanding (Yonker, 2011). Another restriction of online examinations is the inability for students to provide handwritten answers. This is especially important in disciplines where freehand writing or drawing is needed to adequately convey meaningful and accurate answers (González-Tato \& MikicFonte, 2013; Hanson et al., 2014).

The use of computer tablets (or tablet PCs) within educational settings has increased significantly in recent years (Berque et al., 2006; Nakagawa et al., 2010; Manuguerra \& Petocz, 2011; Wright, 2013). Interaction with the hardware via stylus pens, which enables writing in 'digital ink', has become an important feature in the use of tablets and has fostered new pedagogical approaches (Maclaren, 2014). Other beneficial aspects include the ability to install and operate software applications, or 'Apps' (Preez et al., 2012), and the incorporation of wireless internet capability which allows students to access and submit learning tasks online from a greater variety of locations 
(Smith \& Cline, 2011; Anderson et al., 2013; Goh et al., 2013). Online submission of assessment tasks can also significantly expedite exam marking (Banitsas et al., 2010; Bloomfield, 2010). Together, this suggests mobile devices could potentially replace pen and paper for assessment, with improved accessibility for students and markers.

Pen-enabled tablets have been utilised in a variety of learning and assessment contexts. Within the classroom, their use increases student interaction and participation (Rogers \& Cox, 2008; Kamin \& Fagen, 2012), while providing real-time feedback to lecturers (Donovan \& Loch, 2013). Inclusion of tablets in coursework can also reduce student attrition and failure from courses while improving attendance (Koile \& Singer, 2006; Benlloch-Dualde et al., 2010). Tablet usage can also boost student performances in downstream assessment quizzes (Enriquez, 2010), conceptual problem-solving tasks (Kurtz et al., 2014) and literacy (Neumann, 2014). Wireless tablets also promote active learning in peer-assisted study exercises that require online student collaboration, with demonstrated improvement in student self-confidence (Alvarez et al., 2011), engagement (Fagen \& Kamin, 2013) and time efficiency (Devey et al., 2012).

While online assessment is now commonplace, the use of online technologies for high-stakes assessment items is less common (Hillier \& Fluck, 2013). However, pen-enabled tablets have the potential to overcome the limitations of online assessment and may ultimately replace traditional paper-based exams. The incorporation of a pen allows free handwriting and drawing directly on the tablet, which is particularly important where the input of diagrams, equations and pathways are required. This aspect gives the pen-enabled tablet superiority over other online assessment as it can closely replicate paper examinations, while incorporating online submission to facilitate marking. To date, there have only been a small number of studies which explore this potential. In 2007, Göhner et al., proposed a 'hybrid' electronic exam that would allow input via both keyboard and stylus pen handwriting. More recently, Siozos et al., (2009) developed an App that would launch an examination when activated, including again both keyboard and stylus pen input, with students completing the exam showing a significant preference for the tablet over traditional PCs. Although both these studies attempted to replace a paper-based exam with a tabletbased version, the exam format was significantly altered in the process. Therefore, an investigation is warranted into the use of tablet exams identical in format to paper exams, handwritten via a digital pen. This format would closely replicate the traditional examination process, and is the basis of the present study.

In our experience, only a small fraction of students request feedback on their exams. This represents an opportunity lost for students to reflect on their performance and learn from their mistakes (Blair et al., 2013). Indeed, there has been a distinct "failure to integrate feedback into exam-based assessments" (Scoles et al., 2013, p. 632). However, organising exam viewing can present significant scheduling and logistical challenges. Lecturers need to commit time to meet students and may need to liaise with administrators to organise retrieval of exam papers. Students may need to initiate contact with several lecturers to schedule exam viewing sessions. For many students, initiation of such contact is a cultural and personal esteem challenge. These challenges present significant barriers to the provision of feedback on exam performance. To remedy this, a process streamlining the onlinesubmission of exam papers with the online marking of these exams is desirable. Under such circumstances, students could simply access their password-protected, marked papers online. Furthermore, with current advances in online technologies related to assessment marking and feedback, students who took a tablet-based exam could receive more personalised, in situ feedback.

The purpose of this study was to design and evaluate a tablet-based examination App (TabExam) that resembled the traditional paper exam as closely as possible. Exams completed with TabExam were submitted and marked online, with online feedback provided.

Specifically, this study focused on three research questions:

- How do students interact with the tablet under examination conditions?

- Are their performances on the exam affected by the technology when compared to a paper-based exam format?

- To what extent do students seek feedback on their performances in either the TabExam or paper exams? 
These questions were addressed by conducting detailed surveys and a comparison of academic performance on the paper- and tablet-based exams.

\section{Methodology}

The traditional paper exams at our institution are presented on A4 paper in portrait orientation. It was desirable that this size and orientation are matched on the tablet. In addition, a suitably sensitive and user-friendly 'pen-onpaper' perception - one that would facilitate legibly and expedient digital handwriting - was required. Based on these factors, the Android-based Samsung Galaxy Tab 10.1 was chosen, with its inclusive digital stylus pen ('S pen') that interacts with the tablet screen interface as both a selection and a handwriting tool, at a cost of AUD\$500 per tablet.

\section{TabExam Construction}

The TabExam assessment application was developed using Java, Android SDK (Version 4.1.2) and the Samsung S Pen SDK. The Samsung S Pen SDK handled the 'digital ink' components of the application while the Android SDK handled the administration components. The TabExam App was designed to be identical to the paper exam in all aspects of formatting and structure.

Launching the TabExam App on the Samsung Tablet prompted a login with password to authenticate student identity. Examples of pages from the TabExam and the paper exam are shown in Figure 1. Aside from the handwriting function for which the stylus pen was essential, other features were responsive to both stylus pen and touch, such as colour of pen and the ability to erase handwritten text, as well as the 'Undo' and 'Redo' functionalities. A palm-guard, which could be raised or lowered vertically on the tablet screen, was deemed necessary. Scrolling up and down was via a vertical-scroller on the right-hand side of each page, while page turning was performed by tapping on right or left arrows at the bottom of the screen. Student progress could be saved at any time by selecting the 'Save' button. Importantly, all other functions of the tablet were disabled while the TabExam was in progress.

Once the TabExam was completed, the student was instructed to click 'Submit' at the top of any page, resulting in a prompt requesting verification that the exam was completed and ready to submit. A new screen containing student name, number and exam title appeared, allowing students to input a file name and generate a PDF of the completed exam. The next prompt provided web browser access to the course Blackboard ${ }^{\mathrm{TM}}$ page allowing submission of the TabExam PDF to Turnitin ${ }^{\mathrm{TM}}$.

Access to the digital keyboard was possible only during the login and submission stages of this process, allowing students to input usernames, passwords and file names, during the examination interaction with the tablet beingrestricted to the stylus pen or touch.

\section{Participants, Exam Content and Delivery}

The participants of this study were Bachelor of Pharmacy students (13 females and 7 males, 19-21 years old) enrolled in a $3^{\text {rd }}$ year physiology and pharmacology course (BIOM3011) at The University of Queensland, a large, research-intensive Australian university. Participants were informed that the examinations were formative and would not affect their grades, and that they could voluntarily withdraw from the study at any time without prejudice. Ethics approval was obtained from the Behavioural \& Social Sciences Ethical Review Committee at The University of Queensland. The lead investigator of this project contributed the majority of the teaching in BIOM3011, and thus prepared the questions for both the TabExam and paper exam. A six-page document summarising key educational concepts was provided to participants by email one week prior to the exam, allowing time for study. Two exams were prepared, each containing different questions at the same level of complexity. This prevented students from seeing the same examination twice, and yet provided exams of similar difficulty. Each exam contained four multiple-choice questions (1.5 marks each) and three short-answer questions (8 marks each) for a total of 30 marks, with 30-minute duration. TabExam was launched upon activation of the App (Figure 1A), while the other was printed on paper (Figure 1B). 


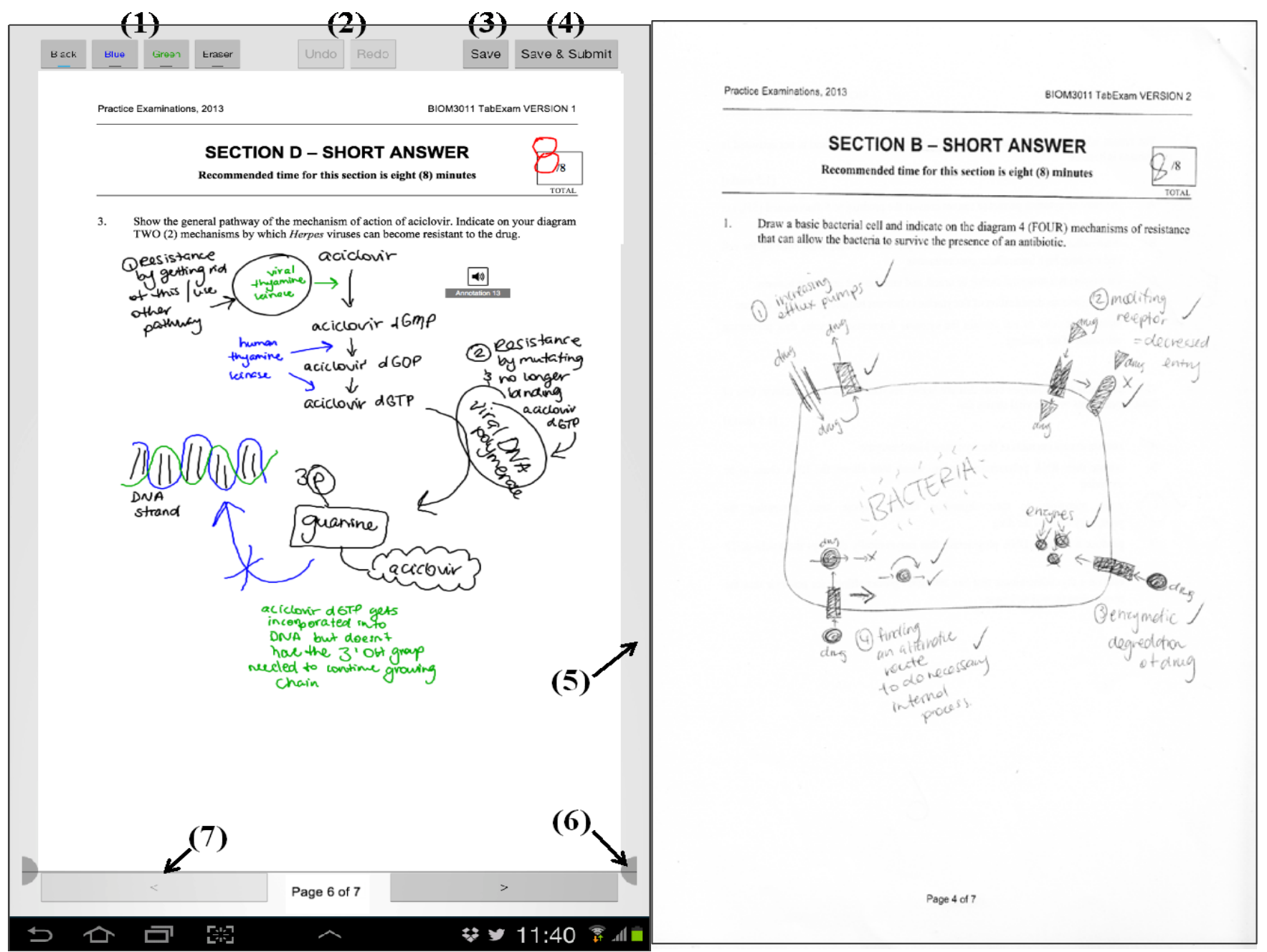

FIG. 1 EXAMPLE OF A PAGE FROM THE TABEXAM (LEFT) AND PAPER EXAM (RIGHT). (1) PEN COLOURS AND ERASER; (2) UNDO AND REDO BUTTONS; (3) A SAVE BUTTON; (4) A SUBMIT BUTTON; (5) VERTICAL-SCROLLING; (6) PALM GUARD AND; (7) ARROWS FOR PAGE TURNING

\section{The Examination Session}

On the day of testing immediately prior to the exam sessions, all participants were given access to the tablet and stylus pen to practice with for 30 minutes. A TabExam on unrelated content was constructed specifically for this purpose, allowing students to become familiar with the tablet, stylus pen and a TabExam, including the processes of starting and saving, adding their details and submission. Following this session, students were randomly divided into two groups of 10, designated Group A and Group B, and were seated for the testing session, held under examination conditions. These two groups differed only in the order with which they completed the tablet and paper exams; thus one group could make use of the tablet first while the other group completed the paper exam, and then these tasks could be switched. In this way, all participants could complete both the tablet and paper exams within a fixed timeframe and the effect of order was minimised. Specifically, the process on the day was as follows:

1. Group A completed the TabExam. Group B completed the paper exam.

2. Group A submitted their TabExams online. Paper exams were collected from Group B.

3. The tablets were transferred from Group A to Group B.

4. Group A completed the paper exam. Group B completed the TabExam.

5. Paper exams were collected from Group A. Group B submitted their TabExams online. 
Immediately after completion of exams, students were asked to complete a survey concerning their ownership and experience with tablets and stylus pens, perceived usefulness and ease of use of the TabExam App and its comparison to the paper-based exam. The survey included 5 open-ended questions and 15 questions on a 5-point Likert scale. The questions were asked in a variety of formats to ensure that the favourable response did not always require agreement. Student responses to the Likert scale questions were analysed to determine the extent of agreement or disagreement with each statement. Responses to the open-ended questions were subjected to inductive thematic analyses, conducted independently by two co-investigators.

\section{Exam Marking and Feedback}

The paper-based exams were marked manually by the lead investigator. The TabExams were loaded onto 'UQMarkup' software (Andrew Dekker, personal communication), which allows online documents (e.g. exams, assignments) to be marked on a tablet computer, with written or audio feedback annotations inserted in situ. Students then access their exam marks and feedback online. Importantly, this software then logs student interactions with the marked document and feedback annotations. The exam scores for Group A and B were collated and subjected to analyse to identify any relationship between student's performance on the TabExam and paper-based exam. Individual student performances on each exam were also compared within groups by paired ttest to identify any order effect. Students were notified of their exam results via email, and were provided with a web link to access their feedback for the TabExam. Within the same email, they were invited to schedule a meeting with the lead investigator to obtain feedback on their performance in the paper exam.

\section{Results}

\section{Exam scores}

Student scores in the TabExam and paper exams were compared (Figure 3). The Pearson's correlation coefficient ( $\mathrm{r}$ $=0.89 ; \mathrm{p}<0.0001$ ) demonstrated a strong, significant correlation in performance between the two exam types. Within each group, there was no significant difference in performance between each exam type, although the mean score was somewhat lower and the variability greater within group A (13.7 \pm 7.0 vs $26.3 \pm 3.7$ for B) because three students performed very poorly on both exams in this group. The significant correlation between individual students' performance on each exam occurred regardless of the order in which the students completed the exams.

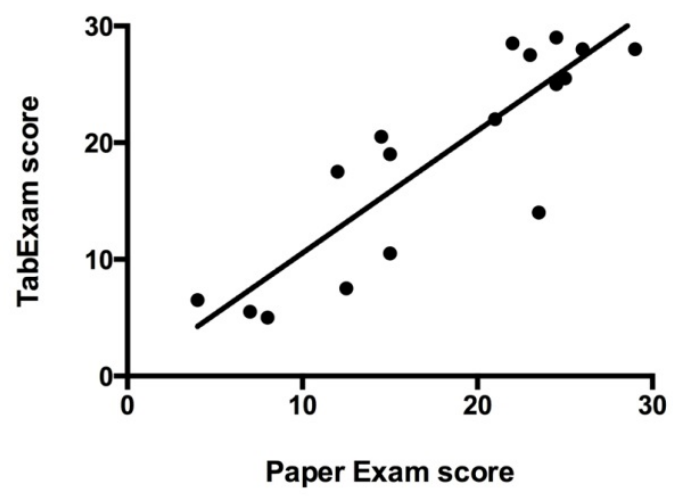

FIG. 3 SCATTER PLOT OF STUDENTS (N=20) TABEXAM AND PAPER EXAM SCORES OUT OF A POSSIBLE 30 MARKS PER EXAM.

\section{Survey Outcomes and Comments}

Student familiarity and ownership of computer tablets was limited, with only six of the 20 students owning a tablet, and just two using a stylus pen. Despite this, 15 students agreed they were confident in using tablets and 12 were

confident with stylus pens. The student responses to open-ended and Likert scale survey questions were grouped thematically into four categories, including: A, Perceived advantages for paper-based exam; B, Perceived advantages for tablet-based exam; C, Neutral stance on tablet-based exam; and D, Perceived disadvantages of a tablet-based exam that can be easily rectified (Table 1). 
TABLE 1 SURVEY QUESTIONS ON USE OF THE COMPUTER TABLET AND COMPARISON OF THE TABEXAM WITH THE PAPER EXAM. ${ }^{A}$ STUDENTS WHO SELECTED AGREE OR STRONGLY AGREE; ${ }^{B}$ STUDENTS WHO SELECTED DISAGREE OR STRONGLY DISAGREE.

\begin{tabular}{|c|c|c|c|}
\hline Question & Agree $^{a}$ & Neutral & Disagree $^{b}$ \\
\hline \multicolumn{4}{|c|}{ Category A: Perceived advantages in using paper-based exam } \\
\hline It was easier to use the paper exam than the tablet exam & 18 & 0 & 2 \\
\hline I could navigate quickly through the pages of the tablet exam & 3 & 5 & 10 \\
\hline I could write quickly using the stylus pen & 5 & 4 & 11 \\
\hline Overall, I still prefer paper exams over tablet exams & 17 & 3 & 0 \\
\hline I was worried about losing my tablet exam from a computer crash & 13 & 2 & 5 \\
\hline I am more comfortable using the paper exam & 16 & 3 & 1 \\
\hline I experienced difficulties in using the tablet exam which would not occur in paper exams & 17 & 1 & 2 \\
\hline \multicolumn{4}{|l|}{ Category B: Perceived advantages in using tablet-based exam } \\
\hline Being able to erase my computer ink was better than erasing real handwriting & 18 & 2 & 0 \\
\hline The stylus pen is too different from real pens & 6 & 4 & 10 \\
\hline It was easy to upload my completed exam onto Turnitin & 17 & 2 & 1 \\
\hline The tablet exam was easy to use & 14 & 2 & 4 \\
\hline \multicolumn{4}{|l|}{ Category C: Neutral stance in the use of tablet-based exam } \\
\hline The tablet exam is a good tool to replace paper exams & 5 & 9 & 6 \\
\hline I DIDN'T feel confident when performing the tablet exam & 7 & 7 & 6 \\
\hline The stylus pen needs to be more sensitive & 7 & 6 & 7 \\
\hline \multicolumn{4}{|c|}{ Category D: Perceived disadvantages in using a tablet-based exam that can be easily rectified } \\
\hline I needed more instructions on how to use the tablet exam & 7 & 1 & 12 \\
\hline There should be a keyboard as well as a stylus pen & 12 & 3 & 5 \\
\hline
\end{tabular}

Responses in category A showed that most students found the paper-based exam easier and more comfortable to use than the TabExam (Table 1). Responses suggest that many students found navigation through the pages of the TabExam difficult, with comments such as "I like to flip pages easily which was not possible, or hard to do" and "It was a bit more awkward flipping from front to back fast. That can take up your time." Most students found they were unable to write quickly with the stylus pen, stating that they required more time and space when completing the TabExam, for example "I am used to paper and find it faster and more comfortable. It's easier to draw structures and my writing was faster, neater and smaller". Some students also reported physical difficulties when using the stylus pen, for example "After a while, I found that using a stylus made my handwriting messier and that it was less comfortable (my hands were painful)." This could be compounded if students had underlying conditions, as one student said "I have broken both hands many times in sport compromising my dexterity. All touch screens are awkward for me." Security was also a negative issue, with students expressing concerns over the potential loss of an electronic exam and technical difficulties that would not be encountered in paper exams. Student comments included "[The tablet] has more issues to worry about e.g. battery dies, system crashed, software crashed etc" and "I think I would have done better on the paper exam because I spent less time worrying about what could go wrong and instead focus on the questions." Many students perceived that they performed better on the paper exam than the TabExam, citing reasons such as level of comfort and time-efficiency, as well as familiarity with and security of the exam. Comments included "I think I would have done better on the paper exam because I spent less time worrying about what could go wrong and instead focused on the questions" and "Better on paper exams because I feel more comfortable writing on the paper and I can write faster".

Contrastingly, some advantages in using the TabExam were expressed (Table 1, Category B). The erase tool was considered an advantage by almost all students, "I like the fact you can erase or undo which I found it useful when doing SAQ [short answer questions]". The online submission process was also considered facile, and in general terms using the tablet was simple and even enjoyable, one student commented "The tablet exam was a lot more fun and therefore the normal pressures/stress of an exam were not as evident."

Students were, on the whole, evenly divided on their overall stance on whether the tablet exam should replace 
paper exams (Table 1, Category C), and one commented that "I can see that exams of this format can someday replace pen and paper." They were neutral in their opinion on confidence in using the TabExam, and appeared to hold no strong position regarding the sensitivity of the stylus pen. One student commented that "I think I performed equally on both, except I took a lot longer on the tablet and felt like I was wasting time for the pen to catch up to my writing. The tablet is good - if you have enough time."

Lastly, perceptions on required improvements of the TabExam were provided (Table 1, Category D). While most students didn't feel that they needed additional instructions be provided (Table 1), they saw the benefit of the training they did have, as one commented "I think if these will become real exams, student will benefit from having a training session like this, just so that they can get used to the system, the stylus pen and how it is run." Students did highlight that more space was required to write answers, "Extra space in which to write would have been nice... the tablet is a little cramped and I struggled to write on it due to the size of the screen" and "The tablet screen size needs to be bigger." Also, the majority agreed with the need for a keyboard, commenting that "A keyboard would have been helpful for short answer questions as my writing is huge on paper and even bigger on the tablet." Some students requested that the exam not be locked in portrait mode, "Allow reorienting the screen from portrait to landscape so as to increase the size of the screen... this would have been helpful". In conclusion, one student said "With a bit of tweaking, this could potentially be really good! An interesting concept..."

\section{Feedback on Exam Performance}

Following marking of all exams, the marked and annotated TabExams were made available online. The time students spent viewing their exam and listening to feedback was recorded (Figure 4). Twelve students accessed their online TabExam feedback. Viewing time ranged from 83 to 819 seconds ( $282 \pm 66 \mathrm{sec}$; mean \pm SEM) and listening time ranged from 27 to 201 seconds (115 $\pm 16 \mathrm{sec}$ ), where approximately $132 \pm 16 \mathrm{sec}$ of audio feedback was made available to each student. Six of these students listened to all audio comments once, three listened to some more than once, while the remaining three did not listen to all available comments. Although all students were invited to view their paper exams for the purpose of receiving feedback, none requested an appointment.

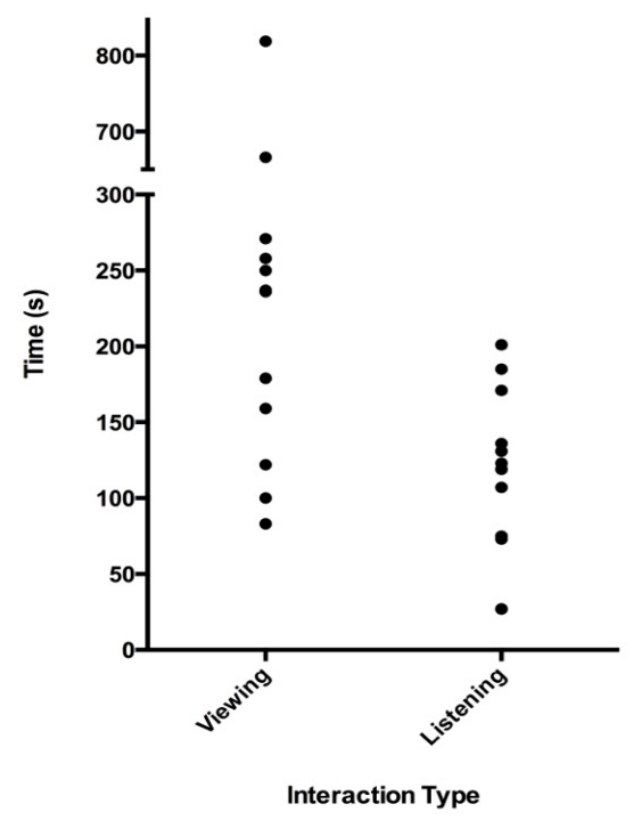

FIG. 4 SCATTER PLOT SHOWING STUDENT FEEDBACK VIEWING AND LISTENING TIMES FOR THE TABEXAM. THE ORDINATE IS TRUNCATED FROM 300-600 SECONDS FOR BREVITY

\section{Discussion}

Few studies to date have directly compared the use of tablet-based exams with paper-based exams, however, this study provides such a comparison at the early, pilot-scale level. Firstly, student performances on the two exam 
platforms were compared and a strong, significant correlation between performance on each exam was found. While this is not unexpected, it highlights that even at this early stage of development the use of the tablet and stylus had no negative impact on student assessment outcomes. This is similar to the findings of Fons (2010) who also found no significant difference between student grades on a tablet-based exam, distributed online, and a comparable pen-and-paper task from a previous semester. Together, these findings suggest that students' exam performance is neither adversely affected nor significantly improved by the use of tablet technology, indicating that programs such as TabExam can accurately capture students' expression of their understanding.

Unlike Fons (2010), the current study also sought to replicate examination conditions, where assessment takes place under timed and supervised settings. These create a more stressful environment under which students must complete assessment tasks (Goonan, 2003). While anxiety often has negative consequences on exam performance (Cassady, 2004; Salend, 2011), the delivery of exams online introduces the problem of student cheating under unsupervised conditions (Turner and Uludag, 2013), which has been one of the key limitations to the use of online technologies for summative assessment. Every attempt was made to provide an experience with the TabExam that was identical to the paper exam, with the exception of its execution on digital format. However, despite similarities in assessment outcomes, students reported demonstrative differences between the two exams. In particular, they were more comfortable using paper, and many reported that they felt they had performed better on the paperbased exam, indicating that the TabExam App in its present state falls short of replicating the paper experience. It has been suggested that the cognitive workload associated with completing an exam on a device such a tablet differs from a paper exam, which can provide a substantially different qualitative experience in student assessment (Noyes et al., 2004; Leeson, 2006). Many students also reported that they were unable to write as quickly on the TabExam compared with paper, which may have contributed to the perception of a reduction in performance. Indeed, slower handwriting in examination conditions has been found to increase stress and decrease exam performances (Connelly et al., 2005). The transition of assessment tasks to a digital setting can itself influence student assessment experiences, whether or not technological problems are encountered (Bennett \& Elliot, 2002; Leeson, 2006).

Student opinions of the stylus pen were mixed. Survey responses showed a neutral stance on its sensitivity, but many reported that they were unable to write quickly and that their writing was larger or messier. Interestingly, most of the students did not consider the pen to be too different from real pens. These findings suggest that digital pen technology has not yet reached the level of a realistic 'pen-on-paper' experience. This was evident by the numerous student comments reflecting the need for a more responsive and precise pen device. When discussing digital pens for tablets, Winkler et al. (2013) state that digital pens for tablets "lack the natural haptic feeling of paper and can often not support input precision" (p. 286). Therefore, enhancements to the present stylus-tablet interaction are needed to facilitate a more realistic handwriting experience. Students also recommended the inclusion of a keyboard to supplement the pen. However, this presents its own problems, as noted by Fischer et al. (2013) "the use of a virtual keyboard limits the speed in which students can translate thoughts into digital text" (p. 19). It also introduces a feature not used in traditional paper exam scenarios, which was avoided in this study in attempting to replicate the paper exam experience.

In contrast to the pen, an overwhelmingly positive viewpoint was expressed on the ability to erase digital ink. However, this may have been influenced by the available screen size, which students regarded as limited, and consequently, they may have perceived a greater need for erasing. Problems associated with tablet screen size have been encountered in previous studies. Theys et al., (2005) tested a variety of different pen-enabled tablets and the most frequent concern raised by students was small screen size. The diagonal length of the interactive screen of the TabExam is 10.1", whereas an A4 page is 11.7". However, at the time of this study, a larger screen size for the Samsung tablet was not available. Students also suggested an option to change from portrait to landscape by shifting the tablet orientation, which would allow for greater horizontal space within which to write. While this feature was included in another study (Siozos et al., 2009), the TabExam was locked in portrait orientation to more closely replicate the paper exam.

While most students agreed that the TabExam online submission procedure was a straightforward process, many 
were concerned that the program may crash during the exam, potentially leading to the loss of the exam in progress. This may, in turn, increase exam anxiety leading to negative effects on exam performance (Stowell \& Bennett, 2010). Despite our reassurances to students before the TabExam that their exam would not be lost, uncertainty remained among many students regarding their exam progress. It is possible that an increasing student familiarity with the use of tablet exams will be accompanied by a reduction of these concerns.

Up to $60 \%$ of students accessed their feedback online, and none requested an exam viewing. This suggests that accessibility of feedback online is an advantage of the TabExam. However, it is also possible that the formative nature of the assessment failed to motivate students adequately to overcome the barriers and seek out feedback on the paper exams. Extensive research has indicated that students predominantly fail to seek out formative feedback (Bailey, 2009), due to a lack of student motivation (Winter \& Dye, 2004; Carless, 2006) and the inconvenience associated with arranging exam viewing sessions (Jones, 2013). This can be remedied by offering students formative online feedback (Gaytan \& McEwen, 2007; Borko et al., 2009; Hatziapostolou \& Paraskakis, 2010; Jones, 2013). Our findings suggest that online access to marked tablet exams does promote student interaction with formative feedback. This promising finding will be a key driver to the use of tablet exam technologies to assess students and supply meaningful feedback.

Students were primarily neutral when asked whether tablet-based exams are suitable replacements of paper exams, suggesting that a convincing argument is yet to be made for the substitution of paper exams with the TabExam. This neutrality was apparent in another report where tablets were used across an entire semester, with students being "evenly split on whether they preferred electronic exams" (Fons, 2010). A survey of more than 230 Midwest university students revealed that student acceptance of tablet PCs is directly driven by students' attitude toward the technology (El-Gayar et al., 2011). Furthermore, perceptions and emotions are key parameters in student acceptance of new technology, where improper implementation of tablet technology can influence the affective component of the student assessment experience (Hall, 2010).

While the TabExam has shown promise in its ability to allow streamlining of student handwritten exams and feedback, technical issues in the tablet's operative use require improvements over this first, pilot version. Digital pen technologies and the responsiveness of stylus-operated tablets are improving, but still fall short of a genuine pen-on-paper experience. When these improvements are made, and an economically viable larger tablet becomes available, there may be greater acceptance for tablet-based exams.

\section{REFERENCES}

[1] Alvarez, C., Brown, C., \& Nussbaum, M. (2011). Comparative study of netbooks and tablet PCs for fostering face-to-face collaborative learning. Computers in Human Behavior, 27(2), 834-844.

[2] Amelung, M., Krieger, K., \& Rosner, D. (2011). E-assessment as a service. Learning Technologies, IEEE Transactions on, 4(2), 162-174.

[3] Anderson, C., Henner, T., \& Burkey, J. (2013). Tablet computers in support of rural and frontier clinical practice. International journal of medical informatics, 82(11), 1046-1058.

[4] Bailey, R. A. (2009). Undergraduate students' perceptions the role and utility of written assessment feedback. Journal of Learning Development in Higher Education, (1).

[5] Banitsas, K., Eliopoulos, G., \& Murray, L. (2010). Using digital pens to expedite the marking procedure. International Journal of Innovation in Education, 1(2), 188-203.

[6] Benlloch-Dualde, J. V., Buendía, F., \& Cano, J. C. (2010). On the design of interactive classroom environments based on the tablet PC technology. In Frontiers in Education Conference (FIE), 2010 IEEE (pp. T4C-1). IEEE.

[7] Bennett, R. E. (2002). Inexorable and inevitable: The continuing story of technology and assessment. Computer-based testing and the Internet, 201.

[8] Berque, D. A., Prey, J., \& Reed, R. H. (Eds.). (2006). The impact of tablet PCs and pen-based technology on education: Vignettes, evaluations, and future directions. Purdue University Press. 
[9] Blair, A., Curtis, S., Goodwin, M., \& Shields, S. (2013). What feedback do students want? Politics, 33(1), 66-79.

[10] Bloomfield, A. (2010, October). Evolution of a digital paper exam grading system. In Frontiers in Education Conference (FIE), 2010 IEEE (pp. T1G-1). IEEE.

[11] Borko, H., Whitcomb, J., \& Liston, D. (2009). Wicked problems and other thoughts on issues of technology and teacher learning. Journal of Teacher Education, 60(1), 3-7.

[12] Carless, D. (2006). Differing perceptions in the feedback process. Studies in Higher Education, 31(2), $219-233$.

[13] Cassady, J. C. (2004). The influence of cognitive test anxiety across the learning-testing cycle. Learning and Instruction, 14(6), 569-592.

[14] Connelly, V., Dockrell, J., \& Barnett, J. (2005). The slow handwriting of undergraduate students constrains overall performance in exam essays. Educational Psychology, 25(1), 99-107.

[15] Conole, G., De Laat, M., Dillon, T., \& Darby, J. (2008). 'Disruptive technologies','pedagogical innovation': What's new? Findings from an in-depth study of students' use and perception of technology. Computers $\mathcal{E}$ Education, 50(2), 511-524.

[16] Devey, A., Hicks, M., Gunaratnam, S., Pan, Y., \& Plecan, A. (2012). Precious MeTL: Reflections on the use of Tablet PCs and collaborative interactive software in peer-assisted study sessions. Journal of Peer Learning, 5(1), 5.

[17] Donovan, D., \& Loch, B. (2013). Closing the feedback loop: engaging students in large first-year mathematics test revision sessions using pen-enabled screens. International Journal of Mathematical Education in Science and Technology, 44(1), 1-13.

[18] Efferth, T. (2013). Ten Years' Experience with an E-Learning Lecture Series on Cancer Biology and Pharmacology. Education Sciences, 3(1), 1-16.

[19] El-Gayar, O., Moran, M., \& Hawkes, M. (2011). Students' Acceptance of Tablet PCs and Implications for Educational Institutions. Journal of Educational Technology \& Society, 14(2).

[20] Enriquez, A. (2010). Enhancing student performance using tablet computers. College Teaching, 58(3), 77-84.

[21] Fagen, W., \& Kamin, S. (2013, March). Measuring increased engagement using tablet PCs in a code review class. In Proceeding of the 44th ACM technical symposium on Computer science education (pp. 465-470). ACM.

[22] Fischer, N., Smolnik, S., \& Galletta, D. F. (2013). Examining the Potential for Tablet Use in a Higher Education Context. In Wirtschaftsinformatik (p. 1).

[23] Fons, J. (2010). A year without paper: Tablet computers in the classroom. The Physics Teacher, 48(7), 481-483.

[24] Göhner, P., Jeschke, S., Natho, N., \& Pfeiffer, O. (2007, November). Design and Implementation of Hybrid Examinations for the Academic Education using Tablet PCs. IEEE Computer Society Conference Publishing Services.

[25] Gikandi, J. W., Morrow, D., \& Davis, N. E. (2011). Online formative assessment in higher education: A review of the literature. Computers \& Education, 57(4), 2333-2351.

[26] Goh, S. C., Galligan, L. A., \& Ku, H. (2013). Wireless tablet PCs for enhanced teaching at an Australian regional university teaching both campus and distance modes. In Proceedings of the 120th American Society for Engineering Education Annual Conference and Exposition (ASEE 2013) (pp. 1-12). American Society for Engineering Education.

[27] Goonan, B. (2003). Overcoming Test Anxiety: Giving Students the Ability to Show What They Know. In Measuring up: Assessment issues for teachers, counselors, and administrators.PDF retrieved from http://files.eric.ed.gov/fulltext/ED480053.pdf.

[28] Hall, G. (2010). Technology's Achilles Heel: Achieving High-Quality Implementation. Journal of Research on Technology in Education, 42(3).

[29] Hatziapostolou, T., \& Paraskakis, I. (2010). Enhancing the Impact of Formative Feedback on Student Learning Through an Online Feedback System. Electronic Journal of e-Learning, 8(2).

[30] Hillier, M., \& Fluck, A. (2013). Arguing again for e-exams in high stakes examinations. In 2013 Australian Society for Computers in Learning and Tertiary Education Conference (pp. 1-11).

[31] Jones, L. (2013). Using Technology to Support the Grading and Distribution of Written Exam Questions for Large Classes. Retrieved from http://ir.lib.uwo.ca/wcse/WCSEThirteen/july10/18/. 
[32] Kamin, W. (2012). A Cross-Platform Framework for Educational Application Development on Phones, Tablets, and Tablet PCs. PDF retrieved from http://slice.cs.illinois.edu/pubs/fagen-kamin-fecs12.pdf.

[33] Kennedy, G., Judd, T., Churchward, A., Gray, K., \& Krause, K. (2008). First year students' experiences with technology: Are they really digital natives. Australasian Journal of Educational Technology, 24(1), 108-122.

[34] Koile, K., \& Singer, D. (2006, September). Improving learning in CS1 via tablet-PC-based in-class assessment. In Proceedings of the second international workshop on Computing education research (pp. 119-126). ACM.

[35] Kurtz, B. L., Fenwick, J. B., Tashakkori, R., Esmail, A., \& Tate, S. R. (2014, March). Active learning during lecture using tablets. In Proceedings of the 45th ACM technical symposium on Computer science education (pp. 121-126). ACM.

[36] Leeson, H. V. (2006). The mode effect: A literature review of human and technological issues in computerized testing. International Journal of Testing, 6(1), 1-24.

[37] Maclaren, P. (2014). The new chalkboard: the role of digital pen technologies in tertiary mathematics teaching. Teaching Mathematics and its Applications, 33(1), 16-26.

[38] Manuguerra, M., \& Petocz, P. (2011). Promoting Student Engagement by Integrating New Technology into Tertiary Education: The Role of the iPad. Asian Social Science, 7(11).

[39] Mogey, N., Paterson, J., Burk, J., \& Purcell, M. (2010). Typing compared with handwriting for essay examinations at university: letting the students choose. Research in Learning Technology, 18(1).

[40] Nakagawa, M., Yoshida, N., Koyama, K., Tsukahara, W., \& Zhu, B. (2010, April). Exam script analysis from a pen and paper device. In Information Technology Based Higher Education and Training (ITHET), 2010 9th International Conference on (pp. 424429). IEEE.

[41] Neumann, M. M. (2014). An examination of touch screen tablets and emergent literacy in Australian pre-school children. Australian Journal of Education, 0004944114523368.

[42] Noyes, J., Garl, \& Robbins, L. (2004). Paper-based versus computer-based assessment: is workload another test mode effect?. British Journal of Educational Technology, 35(1), 111-113.

[43] Preez, V. D., Pearce, B., Hawick, K. A., \& McMullen, T. H. (2012). Human-computer interaction on touch screen tablets for highly interactive computational simulations. In Proc. International Conference on Human-Computer Interaction (pp. 258-265).

[44] Rogers, J., \& Cox, J. (2008). Integrating a single tablet PC in chemistry, engineering, and physics courses. Journal of College Science Teaching, 37(3), 34-39.

[45] Salend, S. J. (2011). Addressing test anxiety. Teaching exceptional children, 44(2), 58-68.

[46] Scoles, J., Huxham, M., \& McArthur, J. (2013). No longer exempt from good practice: Using exemplars to close the feedback gap for exams. Assessment E Evaluation in Higher Education, 38(6), 631-645.

[47] Siozos, P., Palaigeorgiou, G., Triantafyllakos, G., \& Despotakis, T. (2009). Computer based testing using "Digital Ink": Participatory design of a tablet pc based assessment application for secondary education. Computers $\mathcal{E}$ Education, 52(4), 811819.

[48] Smith, M. L., \& Cline, M. A. (2011). Inexpensive Options for a High-Tech Learning Environment. Journal of Science Education and Technology, 20(6), 785-789.

[49] Stowell, J., \& Bennett, D. (2010). Effects of online testing on student exam performance and test anxiety. Journal of Educational Computing Research, 42(2), 161-171.

[50] Theys, M. D., Lawless, K., \& George, S. (2005, October). Tablet computers and the traditional lecture. In Frontiers in Education, 2005. FIE'05. Proceedings 35th Annual Conference (pp. T2G-7). IEEE.

[51] Turner, S. W., \& Uludag, S. (2013, October). Student perceptions of cheating in online and traditional classes. In Frontiers in Education Conference, 2013 IEEE (pp. 1131-1137). IEEE.

[52] Wilkinson, S., \& Rai, H. (2009). Mastering the Online Summative-Assessment Life Cycle. In R. Donnelly, \& F. McSweeney (Eds.) Applied E-Learning and E-Teaching in Higher Education (pp. 347-368). Hershey, PA: Information Science Reference. 
doi:10.4018/978-1-59904-814-7.ch017

[53] Winkler, C., Seifert, J., Reinartz, C., Krahmer, P., \& Rukzio, E. (2013, October). Penbook: bringing pen+ paper interaction to a tablet device to facilitate paper-based workflows in the hospital domain. In Proceedings of the 2013 ACM international conference on Interactive tabletops and surfaces (pp. 283-286). ACM.

[54] Winter, C., \& Dye, V. (2004). An investigation into the reasons why students do not collect marked assignments and the accompanying feedback. CELT Learning and Teaching Projects 2003/04. Retrieved from http://hdl.handle.net/2436/3780.

[55] Wright, S. (2013). The Impact of Technology on Teaching. Journal of Communication Disorders, Deaf Studies $\mathcal{E}$ Hearing Aids. 1:e103. doi: 10.4172/jcdsha.1000e103

[56] Yonker, J. (2011). The relationship of deep and surface study approaches on factual and applied test-bank multiple-choice question performance. Assessment E Evaluation in Higher Education, 36(6), 673-686.

Matthew J. Cheesman is a lecturer in the School of Biomedical Sciences at The University of Queensland. His research interests focus on learning through computer technologies, including mobile learning and virtual laboratories. Please address correspondence regarding this article to the School of Biomedical Sciences, University of Queensland, St. Lucia 4072, Australia.

Prasad Chunduri is a lecturer in the School of Biomedical Sciences at The University of Queensland, where he researches predominantly into areas related to first year higher education including active learning in large first year classes, online teaching and learning technologies particularly relating to assessment and feedback.

Mary-Louise Roy Manchadi is a lecturer and practical tutor coordinator in the School of Biomedical Sciences at The University of Queensland, where she teaches pharmacology and physiology to all year groups of professional and science undergraduate students as well as post-graduate medical students.

Kay Colthorpe is a teaching-focused lecturer in the School of Biomedical Sciences at the University of Queensland. She is the Chair of the Education Research Unit, and her research interests include the development of effective assessment and feedback, science communication, and the design and use of inquiry-based classes to aid critical thinking skills.

Ben Matthews is senior lecturer and deputy director of the interaction design and multimedia design programs at The University of Queensland. His research focuses on methodological issues in the design and analysis of interactive technologies, and developing open forms of participation in design. 